\title{
Convenience store locations prioritization: a fuzzy TOPSIS-GRA hybrid approach
}

\author{
Jyotdeep Singh \\ Mechanical Engineering, Delhi Technological University, Delhi, India \\ Parnika Tyagi \\ Electronics and Communication, Delhi Technological University, Delhi, India, and \\ Girish Kumar and Saurabh Agrawal \\ Mechanical Engineering, Delhi Technological University, Delhi, India
}

\begin{abstract}
Purpose - The objective of the study is to develop a methodology to strategically rank store locations using criteria such as population, store site characteristics, economic considerations, competition and so on to select the most optimal retail convenience store location.

Design/methodology/approach - A case of National Capital Region, India, for a 24-h convenience store was considered for the study and the major criteria that affect the performance of a convenience store are identified, such as population characteristics, economic criteria, competition, consumer accessibility, store size, total cost, site attractiveness and security. Fuzzy AHP is utilized to find the weightage for each criteria and a combination of fuzzy TOPSIS and grey relational analysis (GRA) is applied to rank the alternative using these criteria weight. Further, results obtained are compared with results from fuzzy TOPSIS and fuzzy VIKOR methods. Sensitivity analysis is also performed for ensuring the robustness of the framework.

Findings - It is observed that outcomes do not change under various settling coefficient values, demonstrating that the methodology is very robust. The developed framework will be quite useful to diverse retailers looking to expand and generate substantial profits.

Research limitations/implications - A large sample size of number of locations encourages generalization of results. Strategic ranking of the selected locations is carried out on a few selected criteria. The study was limited by the designated geographical area.

Originality/value - The study contributes to the few available articles on convenience store selection using combination of fuzzy AHP, fuzzy TOPSIS and GRA for a developing country.
\end{abstract}

Keywords Retailing strategy, Convenience store, AHP, TOPSIS, Grey relational analysis

Paper type Research paper

\section{Introduction}

The choice of retail location areas is an important decision for retailing decision-makers (DMs) as it is a long-term decision and higher costs are involved in it. As convenience is of utmost importance to the present buyers, a retail store can thrive or flop exclusively dependent on its location. The reason is that a decent area can pull in and be open to a substantial number of individuals affecting deals and benefits. Subsequently, it is hard to make up for the negative impact of an ill-placed location. A large chunk of convenience store profit depends on how "convenient" it is, whether that convenience comes from the layout, variety, brand or location.

(C) Jyotdeep Singh, Parnika Tyagi, Girish Kumar and Saurabh Agrawal. Published in Modern Supply Chain Research and Applications. Published by Emerald Publishing Limited. This article is published under the Creative Commons Attribution (CC BY 4.0) license. Anyone may reproduce, distribute, translate and create derivative works of this article (for both commercial and non-commercial purposes), subject to full attribution to the original publication and authors. The full terms of this license may be seen at http://creativecommons.org/licences/by/4.0/legalcode

Convenience store locations prioritization

Received 29 January 2020 Revised 5 May 2020 31 August 2020

Accepted 22 October 2020 
MSCRA

2,4

A convenience store is a small retail business that stocks a variety of ordinary items, such as perishables, baby products, desserts, soda pops, common medicines, toiletries, magazines, papers and so on. These are different from general stores and town shops as they do not fall in a rural area and are better alternative to bigger stores. In all the retailing joint frameworks, convenience stores (CVs) have the easiest access to customers. Proper site determination entails much more than simply choosing a site with more visibility and ease of access. Successful research on rivalry, socioeconomics and advertise request are additionally required. Location is considered a prime consideration for retailing and services (Jones et al., 2003). Hence, it becomes significant to give proper thought to decide on an appropriate location to increase foot traffic and revenue.

The motivation for the study comes from the increased interest in the convenience retailing space in India. The trend is likely to gather pace with more players competing to create a dominance in market. With change in time, there has been a slow and gradual change in shopping trends especially for household goods considering criteria such as good quality, good assortment and competitive prices. Owing to these changes there has been a $14.2 \%$ CAGR (compound annual growth rate) increase per year in organized retail sector (PWC, 2017). This motivated multiple brands to enter in convenience retailing business where previously over $90 \%$ market was controlled by unorganized retail shops. Further, India has the most astounding utilization development among the main ten nations positioned by size of family last utilization consumption (HFCE). Moreover, rising urbanization (27\% towards the start of century to $32 \%$ in 2015) and the developing interest of ladies in the workforce are additionally making a period starved purchaser bunch which is probably going to pay a premium for comfort segment. One other purpose behind this change is the ongoing endorsement of Model Shops and Establishment (Regulation of Employment and Condition of Services) Bill. This will provide a legal framework to work 365 days a year and adaptable long periods of activity subsequently supporting the opening of nonstop accommodation stores. Despite the popularity and high growth estimates, there has been limited research done in this domain. Hence, for this research we consider the case of $24 \times 7$ open convenience stores as they are gaining popularity due to their "convenient" nature and due to our fastpaced life.

The research questions that have been addressed in this study are as follows:

(1) Selecting important criteria for convenience store location selection.

(2) Strategically ranking these selected criteria through a suitable technique.

(3) Developing a methodology to strategically rank store locations using criteria such as population, store, site characteristics, economic considerations, competition and so on.

(4) Selecting the most optimal retail convenience store location.

India's organized retail sector market is expected to grow by $83 \%$ by 2021 (Chakravorty, 2019), and convenience stores constitute a majority in it. Thus, selecting the optimal convenience store location becomes a priority in the business strategy of a firm when it is undergoing an expansionary phase whether locally or globally. A convenience store location is selected keeping in mind various criteria/core capabilities that determine its success; in this study, the authors attempt to optimize the selection process by making it more relevant to business owner's needs and the necessities of a developing country. Our study provides a low-cost, easily integrable, practical method to the strategy of industry professionals to grow their business and obtain a competitive advantage.

For the purpose of this research, the authors have studied the retail sector in India and the major opportunities that exist in this sector. The focus of this study is about the location 
selection. Developing a convenience store location ranking methodology in the Indian retail context on the basis of various criteria specific to the sector and region under study is the main contribution of this study

A number of researchers have worked with area assessment for convenience stores. However, there is limited work in Indian context for the determination of convenience store locations. The fact that this study focusses on round-the-clock convenience stores also enhances the originality of this research. In the past, researchers have focussed more on exact estimations rather than the fuzzy environment. There are numerous criteria which should be assessed when choosing where to locate a convenience store. For instance, one of the assessment criteria depends on the population characteristics residing in the chosen territory. Besides, it being difficult to assess human behaviour and model characteristics, socioeconomic factors and behavioural aspects may also not be uniform over an area. Distinguishing these assessment criteria, characterizing the impacts of them on one another and their significance and picking an area require a very much characterized multi-criteria decision-making (MCDM)-based assessment (Burnaz and Topcu, 2006). Apart from the criteria considered in the literature, security is considered as a criterion affecting the location feasibility in the proposed study.

The rest of the paper is arranged as follows. The literature review is discussed in Section 2. The theoretic description of fuzzy analytical hierarchical process (AHP), fuzzy TOPSIS and grey relational analysis (GRA) is provided in Section 3. In section 4, a real-world case study is presented; the results and sensitivity analysis are discussed in Section 5. Finally, the paper is concluded in Section 6.

\section{Literature review}

This section deals with the detailed literature review under two categories; location selection methodologies and factors affecting retail location.

\subsection{Location selection methods}

In recent years, many traditional approaches have been used to solve various MCDM problems. Yang et al. (2008) used AHP (analytical hierarchical method)/ANP (analytical network process) approach to solve a MCDM problem of selecting best facility; however, the research adopted a non-fuzzy methodology and a heuristic approach for alternatives ranking. Chang and Hsieh (2014) used a TOPSIS model to determine best chain store location using five criteria: crowds, store cluster, site features, store site acreages and the proportion of rent expenses against annual sales. Gupta et al. (2018) applied MCDM tools for optimum locations identification for charging of electric vehicles. Bai and Satir (2020) suggested an integrated model using AHP, information entropy theory (IET) and entropy TOPSIS techniques to rate green supplier satisfaction. However, both the researches have adopted a non-fuzzy approach and focussed on limited criteria for deciding best location. Yap et al. (2019) reviewed number of articles for site selection using MCDM.

There were some studies for location selection under fuzzy environment. Kumar et al. (2019) employed fuzzy TOPSIS approach for preferential selection of locations for installing CCTV surveillance system. Singh et al. (2018) applied a fuzzy AHP approach to locate a warehouse in Iranian market; however, the study is limited by focussing only on four major criteria affecting a warehouse location.

The researchers started using integrated approach to exploit the advantages of more than two combined techniques. Gupta et al. (2019) proposed an integrated MCDM approach for green supplier selection using integrated fuzzy AHP and three other, MABAC, WASPAS and TOPSIS. Onüt et al. (2010) developed a combined fuzzy AHP for assigning weights and fuzzy 
MSCRA

2,4

284

TOPSIS approach to locate a shopping store adopting a real-life case of Istanbul, Turkey, driven by major economic shifts in the country. Consequently, Nyaoga et al. (2016) proposed a combined fuzzy TOPSIS-GRA approach to evaluate value chain performance of tea processing chains, the study also focusses on ranking them based on certain pre-defined qualitative criteria and subsequently determining the ranks of performance of value chain forms.

However, several other unconventional methods have also been adopted for optimal location selection. Kaufmann et al. (2000) compared three multi-unit retail location site determination techniques, in particular a successive methodology, a worldwide methodology and a proposed foreseen defer strategy. The authors assessed the after effects of these site choice strategies by utilizing diversion like two-party re-enactment. Malik et al. (2015) used graph theory and matrix approach for selection of locations of collection centres for reverse logistics. Arsovski et al. (2017) proposed a model for location selection for parking lots based on fuzzy AHP and Hurwitz methods. Recently, Shan et al. (2019) developed an algorithm for the optimization of selection of facility location of chain stores in China. Kuo et al. (2002) developed a decision-making system for selecting the best location out of multiple alternatives using an integrated model of fuzzy AHP and artificial neural network. However, model training might be difficult to tackle where there is no data availability. Roig-Tierno et al. (2013) worked on a methodology for location selection for retail stores using geographic information system while integrating it with AHP. Mendes and Themido (2004) discussed use of genetic algorithms for the global problem of the multi-outlet chain configuration.

Lack of data and existence of several conflicting qualitative and quantitative factors determine best alternative location. The aim was to obtain a better relationship between criteria and optimally ranking the alternatives. Hence, owing to the evident superiority of integrated methods, a methodology which combined TOPSIS method with GRA was adopted by the authors. AHP is utilized to ascertain loads for various criteria and a hybrid fuzzy TOPSIS-GRA model is utilized to rank the elective areas. Although there are numerous examples of location selection based on the MCDM approach in the literature, there is no evidence of employing the hybrid fuzzy TOPSIS-GRA method in the field of location selection. The proposed model's results have been compared with the prominent and most used MCDM tools such as fuzzy TOPSIS and fuzzy VIKOR and also the model has been subjected to sensitivity analysis. This research contributes to the scarce literature of convenience store selection using combination of fuzzy AHP, fuzzy TOPSIS and GRA for a developing country.

\subsection{Factors affecting convenience store locations}

As per real-life examples and based on relevant literature and expert opinion, selection of a convenience store location has been deeply influenced by certain criteria and identifying these criteria is the first major step in convenience store location selection process. For selecting the most impactful criteria, a social, economic and geographical landscape has to be understood. Several of these factors have been mentioned by Kuo et al. (2002) that considered criteria such as competition, store characteristics and population characteristics for the selection of convenience store location. Furthermore, Burnaz and Topcu (2006) contemplated accessibility and competition factors in order to select the best location to open a clothing store. Onüt et al. (2010), in their study for locating a shopping store in Istanbul, Turkey, shortlisted population characteristics, degree of competition, accessibility, total cost, attractiveness as criteria affecting optimum location selection. Chang and Hsieh (2014) investigated the best chain store location using selection criteria's such as site features, the proportion of rent expenses against annual sales crowds, store cluster, to name a few. Erbiy1k et al. (2012) used AHP for retail store site selection using shortlisted criteria such as costs, 
competition conditions, traffic density and physical features. Turhan et al. (2013) provided a comprehensive overview on selecting retail store location based on certain factors that impact a store's performance and revenue. Ge et al. (2019) examined optimized superstore site selection incorporating measures such as population density, interest points, distribution of competitors, network of stores, transportations and so on. The authors employed a combination of machine learning and optimization methods for an optimized site selection. As per the expert opinion, security is a major concern for opening a convenience store in developing and underdeveloped countries. As a real-life example: It is well documented that 7-Eleven, a popular round-the-clock franchise, constantly adapts to the population characteristics, economic characteristics of the local market while setting up (LBS, 2013).

For this study, eight criteria are determined for the selection of the best location for opening a round-the-clock convenience store on the basis of the literature review and experts opinion. Refer Table 1 for the literature source for individual criteria. These criteria are: population characteristics, economic considerations, competition, consumer accessibility, store characteristics, total cost, site attractiveness and site security which are denoted as $C_{1}, C_{2}, C_{3}, C_{4}, C_{5}, C_{6}, C_{7}$, and $C_{8}$ respectively. A brief description of these criteria is provided here.

Population characteristics: Any business can't survive without customers and same is true for convenience stores. Thus, they are usually located in areas with population characteristics such as: population density, average age, gender demographics are favourable.

Economic criteria: The main factor that distinguishes convenience stores from unorganized retail stores is the cost and quality of items available for purchase along with additional services such as fast food, ATMs and so on. Thus, economic demographics such as average household income, purchasing power of the population in the trade area of convenience store play a vital role in selection of its location.

Competition: A Convenience store faces competition in the form of unorganized retail store, other convenience stores, big chain food marts and so on. The amount of competition in the trade area of a convenience store directly affects the amount of business it does.

Consumer accessibility: The easiness by which a consumer can visit a convenience store and shop is measured in the form of consumer accessibility, and it is affected by various factors such as road width, available parking spaces and so on. The easier a convenience store to shop, the more business it does.

Store size: The size of a convenience store determines the variety of goods and services it can provide. The size also affects the consumer shopping experience, thus directly affecting its business.

Total cost: The sum of cost associated with a location whether it's leased, bought or rented is called total cost. It is a vital criterion while selecting a location for a CVS as it has a direct effect on the total profit of the business.

\begin{tabular}{lll}
\hline Codes & Criteria & References \\
\hline$C_{1}$ & $\begin{array}{l}\text { Population } \\
\text { characteristics }\end{array}$ & Ingene and Brown (1987), Hoch et al. (1995), Kuo et al. (2002) \\
$C_{2}$ & Economic criteria & Cottrell (1973), Irwin (1986), Yang et al. (2008), Berman and Evans (1995) \\
$C_{3}$ & Competition & Craig (1984), Hoch et al. (1995), Kuo et al. (2002) \\
$C_{4}$ & Consumer accessibility & Irwin (1986), Kuo et al. (2002), Yang et al. (2008), Erbiyık et al. (2012) \\
$C_{5}$ & Store size & Irwin (1986), Karande and Lombard (2005), Erbiy1k et al. (2012) \\
$C_{6}$ & Total cost & Irwin (1986), Tzeng et al. (2002), Erbiy1k et al. (2012) \\
$C_{7}$ & Site attractiveness & Irwin (1986), Kuo et al. (2002), Erbiyik et al. (2012) \\
$C_{8}$ & Security & Based on discussion with experts
\end{tabular}

Convenience store locations prioritization

285 
MSCRA

2,4

\section{6}

Site attractiveness: It is not always necessary that the consumers solely consist of the population residing in the trade area. People from different regions might also act as consumers at times more so when there is a presence of a magnet such as a tourist spots, government buildings, corporate offices and so on.

Security: $24 \times 7$ functionality is one of the features of a convenience store which also differentiates it from the unorganized retail sector, but this time benefit is only possible if the there is sufficient security such as CCTV cameras, regular police patrols and so on. Security also affects the participation of the female gender as both employees and consumers.

\section{Methodology}

Retail site location selection is a tactical assessment. Therefore, for the selection of the most optimum location of the convenience store, MCDM tools have to be taken into consideration. Generally, in MCDM methods the decision-making process is done in the presence of large number of criteria or attributes.

In this research, a hybrid method of fuzzy TOPSIS-GRA is used because fuzzy TOPSIS as an independent approach requires subjective decision-making while weighing of various criteria (Olson, 2004). This major drawback puts hybrid approach of fuzzy AHP and fuzzy TOPSIS-GRA ahead of fuzzy TOPSIS. Furthermore, the traditionally weighted TOPSIS method only calculates the relative distance to the ideal solution, but ignores the curve trend and cannot accurately reflect the reality (Chen 2019). GRA is a measure of the non-linear relationship between sequences and can compensate for the deficiencies of TOPSIS method (Chen 2019). Hence, this paper uses a combined fuzzy TOPSIS-GRA approach, to evaluate and select the best location alternative for opening a convenience store. It then proceeds to verify the feasibility and effectiveness of the model by a series of sensitivity analysis.

The proposed methodology described in this section consists of two parts. First, fuzzy AHP is applied to calculate criteria weights. Next, a hybrid approach of fuzzy TOPSIS-GRA is employed to rank and select the best location alternative. A flowchart for the developed methodological framework for this study is shown in Figure 1. Steps involved in the methodology are detailed in the following subsections.

\subsection{Fuzzy AHP}

In suggested approach, fuzzy AHP is used to get the weights of the shortlisted criteria for choice of the best area to open a convenience store. AHP is an MCDM technique, which is utilized broadly for prioritizing issues in various fields, for example, legislative issues, financial aspects, social and the management issues (Işılklar and Büyüközkan, 2007). Pure AHP has a few deficiencies. The lack of quality related with the mapping of one's discernment or decisions to a number is not considered (Büyüközkan, 2004). AHP works just with accurate and conventional information, while researchers, as a result of their great capacity for subjective information preparing, settle on choices in fuzzy situations (Torfi et al., 2009). The fuzzy augmentation of AHP, when utilized as chief, is generally discovered more advantageous to express interim decisions than fixed esteem decisions because of the fuzzy idea of the examination procedure. A substantial number of studies have utilized AHP incorporated with fuzzy rationale to take care of different issues. Singh et al. (2018) used fuzzy AHP for selection of warehouse location. Büyüközkan (2004) selected best software development strategy using this method.

\subsection{Hybrid fuzzy TOPSIS and GRA approach}

In this section, an integrated fuzzy MCDM approach is exhibited to assess the engaging quality of different convenience store location options. This strategy has been and can be 


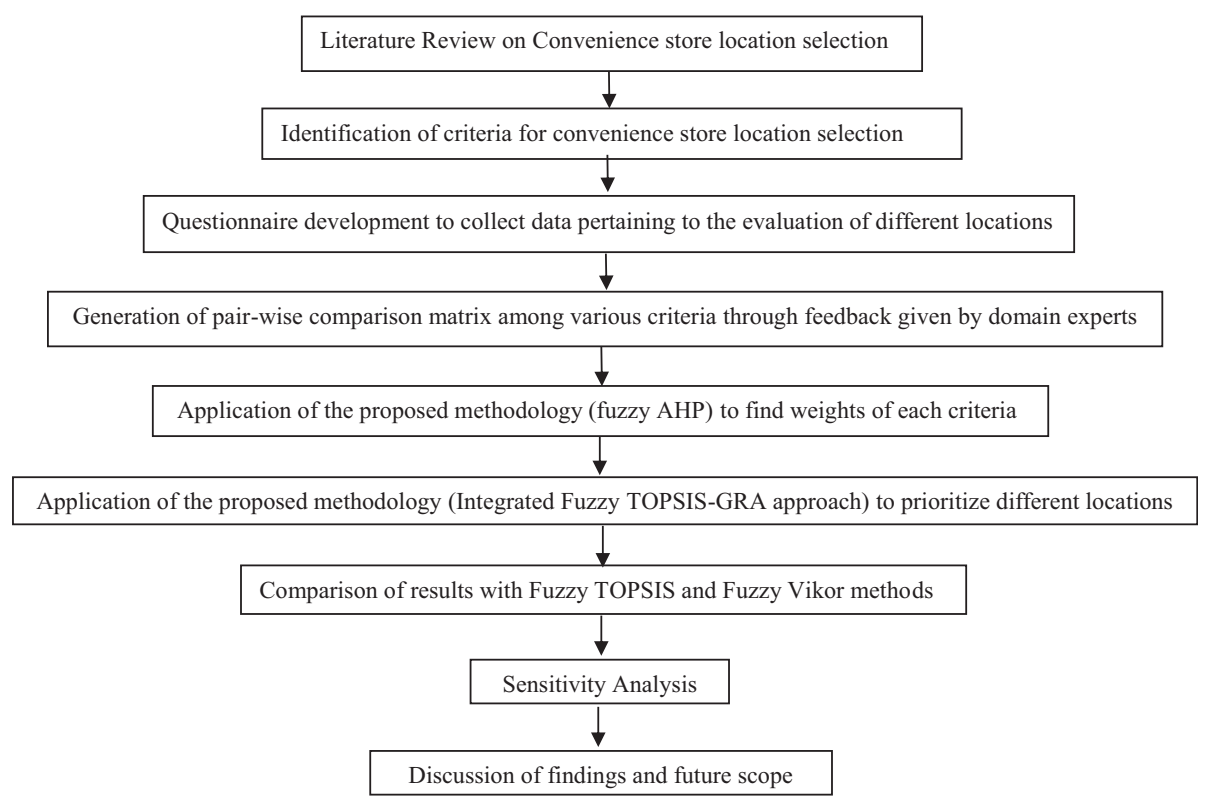

\section{Convenience store locations prioritization}

287

utilized to take care of issues containing uncertain, inconclusive and abstract information. A triangular fuzzy number is utilized to express the locations assessment on different criteria and furthermore locations assessment on choices regarding every paradigm. The membership function of a triangular fuzzy number $\tilde{A}=(j, k, l)$ is defined as per Eq. (1) (see Figure 2).

$$
f_{\tilde{A}}(\mu)=\left\{0, \mu<j ; \frac{\mu-j}{j-k}, j \leq \mu \leq k ; \frac{l-\mu}{l-k}, k \leq \mu \leq l ; 0, \mu>k\right\}
$$

Algebraic operations (addition, subtraction, multiplication, division and reciprocal) on two triangular fuzzy numbers $\tilde{A}=\left(j_{1}, k_{1}, l_{1}\right)$ and $\tilde{B}=\left(j_{2}, k_{2}, l_{2}\right)$ (Kaufmann and Gupta 1991; Dubois and Prade 1980) are expressed as:

$$
\begin{aligned}
& \tilde{A}+\tilde{B} \approx\left(j_{1}+j_{2}, k_{1}+k_{2}, l_{1}+l_{2}\right) \\
& \tilde{A}-\tilde{B} \approx\left(j_{1}-j_{2}, k_{1}-k_{2}, l_{1}-l_{2}\right)
\end{aligned}
$$

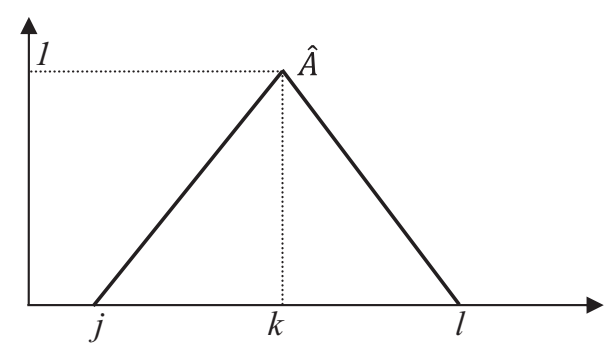

Figure 2. Triangular fuzzy number 
MSCRA

2,4

288

$$
\begin{gathered}
\tilde{A} . \tilde{B} \approx\left(j_{1} \cdot j_{2}, k_{1} \cdot k_{2}, l_{1} \cdot l_{2}\right) \\
\tilde{A} / \tilde{B} \approx\left(j_{1} / j_{2}, k_{1} / k_{2}, l_{1} / l_{2}\right) \\
1 / \tilde{A} \approx\left(1 / l_{1}, 1 / k_{1}, 1 / j_{1}\right)
\end{gathered}
$$

In the proposed strategy, the criteria loads are produced utilizing fuzzy AHP. The positioning of the location options is finished by the integrated fuzzy TOPSIS and GRA strategy. The steps (1-3) utilized Buckley's fuzzy AHP calculation (Buckley, 1985), and the steps (4-12) of the proposed integrated fuzzy TOPSIS and GRA calculation (Chang and Hsieh, 2014) are condensed as follows:

Step 1: A $p \times p$ pair-wise comparison matrix of criteria is created using linguistic variables. Respective fuzzy scale is then replaced with these variables as depicted in the matrix $\tilde{P}$.

$$
\tilde{P}=\left(1 \tilde{p}_{12 \ldots \ldots . . .} \tilde{p}_{1 p} \vdots \cdot \vdots \tilde{p}_{p 1} p_{p 2} 1\right)
$$

Where,

$$
\begin{aligned}
p_{i j} & =\left\{\left(\frac{1}{a_{i}}, \frac{1}{b_{i}}, \frac{1}{c_{i}}\right), \text { for } \forall i>j ;(1,1,1) \text { for } \forall i=j \text { and }\left(a_{i}, b_{i}, c_{i}\right) ; \text { for } \forall i\right. \\
& <j\}
\end{aligned}
$$

In the pair-wise criteria comparison matrix $\tilde{P}$, all the diagonal elements are 1 and among nondiagonal elements, the symmetric elements are reciprocal of each other.

Step 2: Geometric mean technique is used to calculate geometric mean of individual row of $\tilde{P}$ and subsequently a matrix of fuzzy relative weight is constructed using equation (8) (Chang and Hsieh, 2014).

$$
\tilde{r}_{j}=\left[\prod_{l=1}^{p} \tilde{r}_{j l}\right]^{1 / p} \text { for } j, l=1,2, \ldots, p
$$

Step 3: Consequently, the fuzzy weights of each criterion are calculated using Eq. (9)

$$
\tilde{w}_{j}=\tilde{r}_{j} \otimes\left[\prod_{j=1}^{p} \tilde{r}_{j l}\right]^{-1}
$$

Where the fuzzy variable $\tilde{w}_{j}$ is the fuzzy weight for the $j$ th criterion which is the ratio of $j$ th criteria geometric mean $\tilde{r}_{j}$ and summation of geometric mean column. Being a fuzzy number, it is specified as $\tilde{w}_{j}=\left(w_{j 1}, w_{j 2}, w_{j 3}\right)$. Fuzzy weight for the $j$ th criterion has lower, middle and upper values represented as $\left(w_{j 1}, w_{j 2}, w_{j 3}\right)$.

Step 4: A panel of DMs who are expert in retail and convenience store site selection process is selected. A decision matrix consisting of the evaluations of each alternative with respect to each of the selected criteria by a panel of DMs is constructed. For this study, the linguistic variables chosen for this purpose and their corresponding triangular fuzzy numbers are shown in Table 2. The decision matrix for " $q$ " number of alternate locations and " $p$ " number of criteria is expressed as Eq. (10).

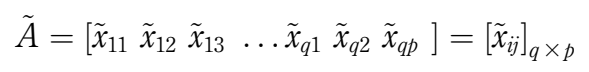


Where $\tilde{x}_{i j}=\frac{1}{K}\left[\tilde{x}_{i j}^{1}+\tilde{x}_{i j}^{2}+\cdots+\tilde{x}_{i j}^{K}\right]=\frac{1}{K} \sum_{e=1}^{K} \tilde{x}_{i j}^{e}$ that is, it is average of $k$ expert rating as all experts are given equal weights.

Where performance rating of alternative $A_{i}$ for criterion $C_{j}$ is $\tilde{x}_{i j} ; i=1,2, \ldots, q$; $j=1,2, \ldots, p$. When it is assessed by $k$ th expert, $\tilde{x}_{i j}$ is defined as $\left(m_{i j}^{k}, n_{i j}^{k}, p_{i j}^{k}\right)$, a triangular fuzzy number.

Step 5: Normalization of the fuzzy decision matrix is established on the traits of two types of criteria which are smaller-the-better (cost) criteria and larger-the-better (benefit) respectively.

For larger the better criteria, normalization is done using Eq. (11).

$$
\frac{\tilde{r}_{i j}=\tilde{x}_{i j}-\min \left(\tilde{x}_{i j}\right)}{\left(\tilde{x}_{i j}\right)-\min \left(\tilde{x}_{i j}\right)}
$$

Where $\tilde{x}_{i j}$ is the element of decision matrix $A_{i}$ obtained in previous step.

For smaller the better criteria, normalization is done using Eq. (12).

$$
\frac{\tilde{r}_{i j}=\max \left(\tilde{x}_{i j}\right)-\tilde{x}_{i j}}{\left(\tilde{x}_{i j}\right)-\min \left(\tilde{x}_{i j}\right)}
$$

Step 6: The multiplication operation between the normalized decision matrix and the criteria weights gives the weighted decision matrix in the normalized form. The weighted normalized decision matrix $V$ for individual criterion is expressed by Eq. (13).

$$
\tilde{V}=\left[\tilde{v}_{i j}\right]_{p \times q} \text { for } i=1,2,3, \ldots p ; \quad j=1,2, \ldots, q
$$

\begin{tabular}{|c|c|c|c|c|c|c|c|c|c|c|}
\hline & & $\mathrm{C} 1$ & $\mathrm{C} 2$ & C3 & $\mathrm{C} 4$ & $\mathrm{C} 5$ & C6 & $\mathrm{C} 7$ & C8 & \\
\hline \multirow[t]{4}{*}{$L_{1}$} & DM1 & $(7,9,10)$ & $(5,7,9)$ & $(7,9,10)$ & $(5,7,9)$ & $(5,7,9)$ & $(7,9,10)$ & $(5,7,9)$ & $(5,7,9)$ & \\
\hline & DM2 & $(5,7,9)$ & $(5,7,9)$ & $(5,7,9)$ & $(7,9,10)$ & $(3,5,7)$ & $(7,9,10)$ & $(5,7,9)$ & $(7,9,10)$ & \\
\hline & DM3 & $(5,7,9)$ & $(7,9,10)$ & $(7,9,10)$ & $(7,9,10)$ & $(7,9,10)$ & $(5,7,9)$ & $(7,9,10)$ & $(5,7,9)$ & \\
\hline & DM4 & $(7,9,10)$ & $(5,7,9)$ & $(7,9,10)$ & $(7,9,10)$ & $(5,7,9)$ & $(5,7,9)$ & $(3,5,7)$ & $(5,7,9)$ & \\
\hline \multirow[t]{4}{*}{$L_{2}$} & DM1 & $(5,7,9)$ & $(3,5,7)$ & $(0,1,3)$ & $(3,5,7)$ & $(5,7,9)$ & $(3,5,7)$ & $(1,3,5)$ & $(0,1,3)$ & \\
\hline & DM2 & $(3,5,7)$ & $(3,5,7)$ & $(1,3,5)$ & $(1,3,5)$ & $(3,5,7)$ & $(1,3,5)$ & $(1,3,5)$ & $(1,3,5)$ & \\
\hline & DM3 & $(3,5,7)$ & $(5,7,9)$ & $(0,1,3)$ & $(1,3,5)$ & $(3,5,7)$ & $(3,5,7)$ & $(0,1,3)$ & $(1,3,5)$ & \\
\hline & DM4 & $(5,7,9)$ & $(7,9,10)$ & $(0,1,3)$ & $(0,1,3)$ & $(3,5,7)$ & $(3,5,7)$ & $(3,5,7)$ & $(0,1,3)$ & \\
\hline \multirow[t]{4}{*}{$L_{3}$} & DM1 & $(3,5,7)$ & $(3,5,7)$ & $(1,3,5)$ & $(3,5,7)$ & $(0,1,3)$ & $(5,7,9)$ & $(5,7,9)$ & $(3,5,7)$ & \\
\hline & DM2 & $(3,5,7)$ & $(1,3,5)$ & $(3,5,7)$ & $(5,7,9)$ & $(3,5,7)$ & $(7,9,10)$ & $(5,7,9)$ & $(1,3,5)$ & \\
\hline & DM3 & $(5,7,9)$ & $(3,5,7)$ & $(1,3,5)$ & $(1,3,5)$ & $(1,3,5)$ & $(3,5,7)$ & $(7,9,10)$ & $(3,5,7)$ & \\
\hline & DM4 & $(1,3,5)$ & $(5,7,9)$ & $(3,5,7)$ & $(5,7,9)$ & $(1,3,5)$ & $(5,7,9)$ & $(5,7,9)$ & $(5,7,9)$ & \\
\hline \multirow[t]{4}{*}{$L_{4}$} & DM1 & $(1,3,5)$ & $(3,5,7)$ & $(0,1,3)$ & $(1,3,5)$ & $(3,5,7)$ & $(1,3,5)$ & $(5,7,9)$ & $(1,3,5)$ & \\
\hline & DM2 & $(1,3,5)$ & $(0,1,3)$ & $(0,1,3)$ & $(1,3,5)$ & $(1,3,5)$ & $(1,3,5)$ & $(5,7,9)$ & $(3,5,7)$ & \\
\hline & DM3 & $(3,5,7)$ & $(1,3,5)$ & $(0,1,3)$ & $(5,7,9)$ & $(3,5,7)$ & $(0,1,3)$ & $(3,5,7)$ & $(5,7,9)$ & \\
\hline & DM4 & $(0,1,3)$ & $(3,5,7)$ & $(1,3,5)$ & $(3,5,7)$ & $(3,5,7)$ & $(1,3,5)$ & $(5,7,9)$ & $(5,7,9)$ & \\
\hline \multirow[t]{4}{*}{$L_{5}$} & DM1 & $(5,7,9)$ & $(1,3,5)$ & $(3,5,7)$ & $(5,7,9)$ & $(5,7,9)$ & $(1,3,5)$ & $(5,7,9)$ & $(3,5,7)$ & \\
\hline & DM2 & $(3,5,7)$ & $(0,1,3)$ & $(1,3,5)$ & $(3,5,7)$ & $(3,5,7)$ & $(3,5,7)$ & $(7,9,10)$ & $(1,3,5)$ & \\
\hline & DM3 & $(5,7,9)$ & $(1,3,5)$ & $(1,3,5)$ & $(3,5,7)$ & $(3,5,7)$ & $(5,7,9)$ & $(3,5,7)$ & $(1,3,5)$ & \\
\hline & DM4 & $(7,9,10)$ & $(3,5,7)$ & $(5,7,9)$ & $(1,3,5)$ & $(3,5,7)$ & $(1,3,5)$ & $(7,9,10)$ & $(0,1,3)$ & \\
\hline \multirow[t]{4}{*}{$L_{6}$} & DM1 & $(3,5,7)$ & $(1,3,5)$ & $(0,1,3)$ & $(1,3,5)$ & $(3,5,7)$ & $(3,5,7)$ & $(7,9,10)$ & $(1,3,5)$ & \\
\hline & DM2 & $(5,7,9)$ & $(3,5,7)$ & $(0,1,3)$ & $(5,7,9)$ & $(3,5,7)$ & $(5,7,9)$ & $(5,7,9)$ & $(0,1,3)$ & Table 2. \\
\hline & DM3 & $(3,5,7)$ & $(0,1,3)$ & $(1,3,5)$ & $(3,5,7)$ & $(1,3,5)$ & $(1,3,5)$ & $(7,9,10)$ & $(0,1,3)$ & Responses of decision- \\
\hline & DM4 & $(5,7,9)$ & $(3,5,7)$ & $(3,5,7)$ & $(3,5,7)$ & $(5,7,9)$ & $(3,5,7)$ & $(7,9,10)$ & $(0,1,3)$ & makers \\
\hline
\end{tabular}

where, $\tilde{v}_{i j}=\tilde{r}_{i j} \times \tilde{w}_{j}$ and being a fuzzy number, it is expressed as
Convenience store locations prioritization 
MSCRA

2,4

290

$\tilde{v}_{i j}=\left(m_{i j}^{*}, n_{i j}^{*}, p_{i j}^{*}\right), i=1,2,3, \ldots q ; \quad j=1,2, \ldots, p$; For $q$ alternates and $p$ criteria

Step 7: Fuzzy positive ideal solution (FPIS) and fuzzy negative solution (FNIS) are obtained from the weighted normalized decision matrix $V$ using Eqn (14) and (15) respectively.

$$
\begin{gathered}
\tilde{V}^{+}=\left(\tilde{v}_{j}^{+}\right)=\left(\tilde{v}_{1}^{+}, \tilde{v}_{2}^{+}, \ldots, \tilde{v}_{p}^{+}\right), j=1,2,3, \ldots p \\
\tilde{V}^{-}=\left(\tilde{v}_{1}^{-}\right)=\left(\begin{array}{lll}
\tilde{v}_{1}^{-}, & \tilde{v}_{2}^{-}, \ldots, & \tilde{v}_{p}^{-}
\end{array}\right), j=1,2,3, \ldots p
\end{gathered}
$$

where $v_{j}^{-}=\left(m_{j}^{-}, n_{j}^{-}, p_{j}^{-}\right)$and $v_{j}^{+}=\left(m_{j}^{+}, n_{j}^{+}, p_{j}^{+}\right), j=1,2,3, \ldots p$ and these are the lowest values for FNIS and highest values for FPIS for a criterion in the given column.

Step 8: In this step, separation distances from FPIS and FNIS are calculated. There are various methods to calculate the separation measures $\tilde{V}_{j^{*}}^{d^{+}}$from FPIS and $\tilde{V}_{j^{*}}^{d^{-}}$FNIS of each alternative to resolve grey relational coefficient of every alternative. Some of these method are: normalized Hamming distance $(l)$, normalized Euclidean distance $(h)$, Hamming distance $(d)$, Euclidean distance $(c)$. This study is based on expansion of Burillo and Bustince's technique (1996) to calculate grey relational coefficient based on the Hamming distance $(d)$. The separation measures $\tilde{V}_{j^{*}}^{d^{+}}$from FPIS and $\tilde{V} \tilde{j}^{*}$ NIS of each alternative are evaluated using Eqn. (11) and (12).

$$
\begin{aligned}
& \tilde{V}_{j^{*}}^{d^{+}}=\frac{1}{4} \sum_{i=1}^{q}\left[\left|m_{i j}^{*}-m_{i}^{+}\right|+\left|n_{i j}^{*}-n_{i}^{+}\right|+\left|p_{i j}^{*}-p_{i}^{+}\right|\right] \\
& \tilde{V}_{j^{*}}^{d^{-}}=\frac{1}{4} \sum_{i=1}^{q}\left[\left|m_{i j}^{*}-m_{i}^{-}\right|+\left|n_{i j}^{*}-n_{i}^{-}\right|+\left|p_{i j}^{*}-p_{i}^{-}\right|\right]
\end{aligned}
$$

Step 9: The following equation is used to generate grey relational coefficient of individual alternative from FPIS and FNIS respectively.

$$
\frac{\gamma^{+}\left(\tilde{V}_{j^{+}}^{d^{+}}\right)=\min _{i} \min _{j} \tilde{V}_{j^{j^{+}}}^{d^{+}}+\zeta \max _{i} \max _{j} \tilde{V}_{j^{*}}^{d^{+}}}{\tilde{V}_{j^{*}}^{d^{+}}+\zeta \max _{i} \max _{j} \tilde{V}_{j^{*}}^{d^{+}}}
$$

Here, the $\zeta$ is resolving coefficient which is usually taken as 0.5

$$
\frac{\gamma^{-}\left(\tilde{V}_{j^{*}}^{d^{-}}\right)=\min _{i} \min _{j} \quad \tilde{V}_{j^{*}}^{d^{-}}+\zeta \max _{i} \max _{j} \quad \tilde{V}_{j^{*}}^{d^{-}}}{\tilde{V}_{j^{-}}^{d^{-}}+\zeta \max _{i} \max _{j} \quad \tilde{V}_{j^{*}}^{d^{-}}}
$$

Step 10: Calculation of grey relational grade from grey relational coefficient of individual alternative using Eqn. (20) and (21).

$$
d_{i}^{+}=\sum_{j=1}^{q} \gamma^{+}\left(\tilde{V}_{j^{+}}^{d^{+}}\right)
$$




$$
d_{i}^{-}=\sum_{j=1}^{q} \gamma^{-}\left(\tilde{V}_{j^{*}}^{d^{+}}\right)
$$

Convenience store locations prioritization

Step 11: The closeness coefficient $\mathrm{CC}_{i}$ defined as closeness to the ideal solution is calculated by the following expression.

$$
\mathrm{CC}_{i}=\frac{d_{i}^{+}}{d_{i}^{-}}
$$

Step 12: The preference order is ranked. Using the index calculated in the previous step, a decreasing order is followed by the alternatives.

\section{Case illustration}

To illustrate fuzzy AHP-fuzzy TOPSIS-GRA hybrid approach suggested in this work, a case study for a nationwide round-the-clock convenience store chain has been taken.

\subsection{Profile of the case company}

This study has considered an Indian round-the-clock convenience store chain known as ABC which is anticipating extending its business in the National Capital Region (NCR) of Delhi through widening its market reach and nearness in Delhi and other close-by territories. ABC is India's sole composed retail chains in the "round the clock" accommodation store group propelled with the vision of turning into a vital piece of the lives of individuals in each network.

The premier $\mathrm{ABC}$ convenience store was opened in 2004. The company comprises of stores open 24 h every day, seven days a week. ABC store offers more than 3,500 items and administrations. Its contributions and format of stores are intended to take into account clients who are continually in a hurry. The New Delhi-based organization as of now works as $\mathrm{ABC}$ stores in the NCR and other northern areas of the world's second-most crowded nation. The organization has extension plan of $\mathrm{ABC}$ outlets in near future. The stores' main value proposition is to cater to customers who are constantly on the go, by being situated at close proximity to their homes and offices.

NCR of Delhi was chosen for this study, as the company plans to expand in New Delhi and the nearby areas such as Gurugram and so on. Delhi-NCR has been drawing in a huge workforce from smaller urban areas and rustic territories; it has caused an extensive increment in the number of inhabitants in the enormous urban areas of India. The development in populace in these metropolitan urban areas additionally has developed new spending interest areas. Rapid urbanization and higher disposable income have created new spending demand areas and customers have now started to choose convenience over price.

\subsection{Data collection}

Based on the review of relevant literature and the experience of a team of experts, eight criteria are determined for the selection of the best location for opening a convenience store. The team of experts comprises of four specialists in both the fields of academia and industry. The first two experts are professors in the field of operations research and supply chain management at premier management and engineering institutes in the country and have high-impact research in the field of MCDM. The rest two experts belong from the industry and are senior managers in the parent company chosen for this study. Detailed questionnaire was sent to the aforementioned experts. A lot of face-to-face interviews were 
MSCRA also held to determine the shortlisted criteria. The potential locations are Safdarjung 2,4 Development Area (SDA) Market; Chattarpur Enclave; Prashant Vihar; Dwarka, Sector-22; Global Business Park, Gurgaon and Windsor IT Park, Noida which are denoted as $L_{1}, L_{2}$, $L_{3}, L_{4}, L_{5}$ and $L_{6}$, respectively. All these identified location sites belong to the National Capital Territory of Delhi region.
SDA Market, Safdarjung

(1) It is situated opposite to IIT Delhi and near NIFT, New Delhi.

(2) Situated in a busy market having wide variety of restaurants and clubs.

(3) Good public transport connectivity.

(4) High competition in the trade area.

(5) Good brand loyalty in the trade area.

Chattarpur Enclave

(1) Situated near one of the fanciest residential areas in South Delhi.

(2) Residents have high household monthly income and purchasing power.

(3) Very low degree of competition in the trade area.

(4) Good parking convenience.

(5) Great store visibility.

(6) Situated on main road.

(7) Security concerns near the site.

Prashant Vihar, Rohini

(1) Residential area nearby with high population density.

(2) High site attractiveness; surrounded by magnets such as cinemas, markets.

(3) Great public transport connectivity, metro station nearby.

(4) Low degree of competition in the trade area.

(5) Low brand loyalty.

Sector-22, Dwarka

(1) Residential area nearby with low land cost.

(2) High site attractiveness; surrounded by magnets such as schools and cinemas.

(3) Low degree of competition in the trade area.

(4) High population growth rate.

(5) Good public transport connectivity.

Global Business Park, Gurgaon

(1) High site attractiveness; surrounded by magnets such as corporate offices.

(2) High expected demand at night due to large number of MNCs in the trade area.

(3) Great public transport connectivity, metro station nearby. 
(4) Low degree of competition in the trade area.

Sector-125, Noida

(1) It is situated near developing business centre with large number of MNCs.

(2) Very low degree of competition in the trade area.

(3) High site attractiveness; surrounded by magnets such as public parks, bird sanctuary and so on.

(4) High security concerns near the site.

(5) Good parking convenience.

\subsection{Evaluation of criteria weights}

The group of experts decides the overall significance of the criteria utilizing the idea of semantic variable and fuzzy AHP. The area choices are evaluated utilizing etymological factors. The pair-wise comparison matrix is constructed based on opinion of the four experts for following Eq. (7). Further, fuzzy relative weight matrix for all criteria is obtained based on Eqs. (8) and (9) and the results are shown in Table 3.

From Table 3 , it is observed that the maximum priority weight achieved among all the different criteria is for the total cost followed by the population characteristics. This implies that to select the optimal convenience store location, the organizations should give a lot of emphasis on the total cost which comprises the ownership, renting plus maintained cost of that particular area/locality and also the population characteristics which include the population demographics such as age, gender, education levels and so on.

\subsection{Ranking of alternatives}

Four experts were chosen to assess the location options dependent on their expertise. All specialists were having over ten years of involvement in the area of retail and were functioning as senior researchers, senior managers and territory heads in the organization. At that point every individual expert assessed every one of the area selected based on the eight shortlisted criteria.

A fuzzy decision matrix is constructed using Eqs. (10), and it is shown in Table 2 for all the DMs $j=1,2,3,4$. The average fuzzy performance values are computed giving equal importance to all the DMs.

Further, the normalized fuzzy decision matrix is determined by utilizing Equations (11) and (12). The weighted fuzzy standardized matrix is determined by utilizing Eq. (12) concerning the fuzzy weights of the criteria which are acquired utilizing fuzzy AHP (Equations 7-9). Additionally, the fuzzy positive (FPIS) and fuzzy negative ideal solutions (FNIS) are evaluated by utilizing Equations (14) and (15), and these are given in Table 4.

\begin{tabular}{ll}
\hline Weight & Criteria \\
\hline $0.049,0.141,0.437$ & Population characteristics \\
$0.025,0.082,0.213$ & Economic criteria \\
$0.082,0.111,0.213$ & Competition \\
$0.035,0.107,0.343$ & Consumer accessibility \\
$0.016,0.039,0.142$ & Store size \\
$0.052,0.133,0.451$ & Total cost \\
$0.019,0.072,0.152$ & Site attractiveness \\
$0.037,0.116,0.343$ & Security \\
\hline
\end{tabular}

Convenience store locations prioritization 
MSCRA

2,4

294

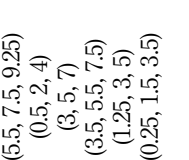

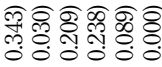

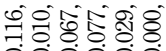

000000

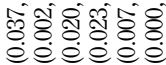

ลิธิชํำชิำ

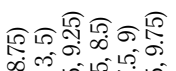

궁둥규.

กิช

O. ․․ㅇ․ㅇ.

स⿺辶َ

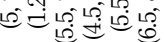

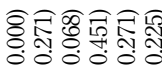

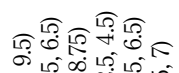

का 1000 เ

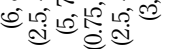

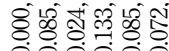

000000

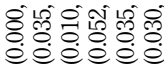

๙ุํㅇ

0

ஸे

종ำ

ปิ่

용

é

낭ㅇํㅇ

ले

00

กิ่

é

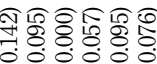

สิริ

约约约约

$\infty$ 10 10.0

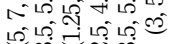

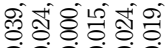

000000

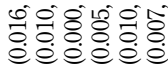

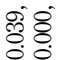

0

仓ํํㅇ

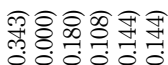

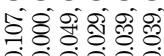

เิ่ 150 ำ

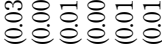

लำ

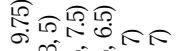

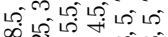

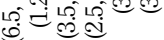

등용

เि

¿ே

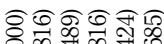

웅요

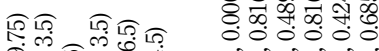

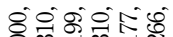

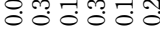

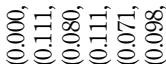

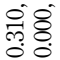

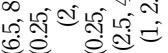

ت̇

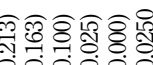

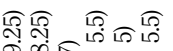
L 20.000

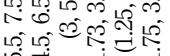

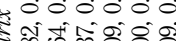

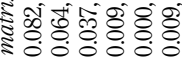
过

กิร

กิ

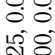

농

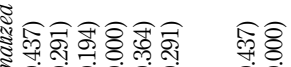
ॠ

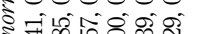
न

的的的

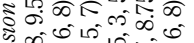

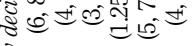
खิ NO0.0 ₹

FPIS and FNIS values of matrix

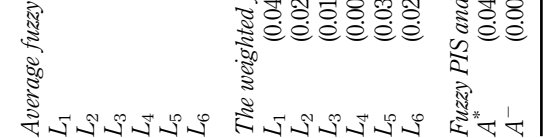


Next, the separation measures $\tilde{V}_{j^{*}}^{d^{+}}$from FPIS and $\tilde{V}_{j^{*}}^{d^{-}}$FNIS of each alternative are evaluated using Eqn. (16) and (17). The grey relational coefficient of each alternative from FPIS and FNIS is calculated using Equations (18) and (19). Then, the grey relational grade is calculated (Equations 20-21), and these are shown in Table 5. Finally, the closeness coefficient using Eqn. (22) of each alternative is calculated and is shown in Table 6. Here, the resolving coefficient is taken to be $\zeta=0.5$.

\section{Results and discussion}

The $\mathrm{CC}_{i}$ values of each location alternative $L_{1}, L_{2}, L_{3}, L_{4}, L_{5}$ and $L_{6}$ are found out to be 1.607, $0.919,0.928,1.097,1.012$ and 0.986 respectively. Therefore, the ranking order of the six location alternatives is $L_{1}>L_{4}>L_{6}>L_{5}>L_{3}>L_{2}$. Thus, it is clear that SDA Market is the most appropriate location alternative to open a convenience store. It is followed by Sector-22 Dwarka, then by Global Business Park, Gurgaon; Windsor IT Park, Sector-125, Noida; Prashant Vihar and finally by Chattarpur Enclave.

The following reasons can be attributed for selecting SDA Market as the most appropriate location alternative to open a convenience store: site attractiveness (vicinity of popular universities such as IIT Delhi and NIFT, New Delhi, and it being a busy market having wide variety of restaurants and cafes which are open late into the night, thus increasing the demand for round-the-clock establishments), population characteristics (young crowd in need of essentials and food items round-the-clock), consumer accessibility (It has great public transport connectivity with metro stations being in close vicinity of the market), competition (There are no stores which solve the problem of round-the-clock convenience in the vicinity).

Based on our observations across different criteria and different locations, we can conclude that given the fact that the high cost of the SDA Market as a location alternative negatively affects the $\mathrm{CC}_{i}$ ranking of a location, while other favourable criteria override cost to generate positive results. It is observed from the discussion earlier that even though a location alternative is not the most optimal one in terms of individual attributes, the ranking comes out on the basis of the generation of a score based on the consideration of all the criteria considered in this study. Out of the six location alternatives, one of the location alternatives emerged as the clear winner but the rest with their respective scores are quite tightly scored demonstrating the highly sensitive nature of the location alternatives. This further implies that management authorities of the respective organizations should follow a logical and scientific approach for choosing the location of the convenience store. As a result of the study, we find that the proposed method is practical for ranking alternatives with respect to multiple conflicting criteria.

Furthermore, to authenticate the effectiveness and applicability of the methodology proposed in this study, a relative study is applied with other approaches. The proposed hybrid fuzzy TOPSIS-GRA methodology and the results obtained from it are compared with the results derived from two of the most widely used MCDM tools: fuzzy TOPSIS and fuzzy VIKOR.

In this research, a hybrid method of fuzzy TOPSIS-GRA is used because fuzzy TOPSIS as an independent approach requires subjective decision-making while weighing of various criteria (Olson, 2004). This major drawback puts hybrid approach of fuzzy AHP and fuzzy TOPSIS-GRA ahead of fuzzy TOPSIS. Furthermore, the traditionally weighted TOPSIS method only calculates the relative distance to the ideal solution, but ignores the curve trend and cannot accurately reflect the reality (Chen 2019). GRA is one of the best methods to make decisions under business environment. It is a measure of the non-linear relationship between sequences and can compensate for the deficiencies of TOPSIS method (Chen 2019). Hence, this paper uses a combined fuzzy TOPSIS-GRA approach, to evaluate and select the best location alternative for opening a convenience store.

Convenience store locations prioritization 
MSCRA

2,4

\section{6}

\begin{tabular}{|c|c|}
\hline$\tau$ & 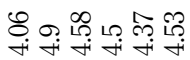 \\
\hline$\frac{t}{\tau}$ & 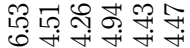 \\
\hline $0^{\infty}$ & జై \\
\hline$心$ & サ. \\
\hline 0 & 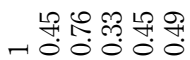 \\
\hline しో & 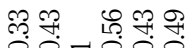 \\
\hline$U^{*}$ & ๙ึ. \\
\hline$\infty^{\infty}$ & 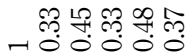 \\
\hline$\sigma^{N}$ & 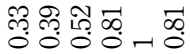 \\
\hline$\circlearrowleft$ & 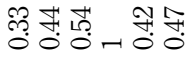 \\
\hline $0^{\infty}$ & 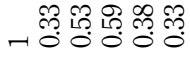 \\
\hline 5 & 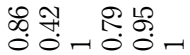 \\
\hline 0 & ఇָׁ \\
\hline ن & - \\
\hline U & 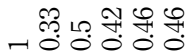 \\
\hline$\infty^{\infty}$ & 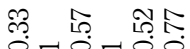 \\
\hline N & r \\
\hline$\mho$ & 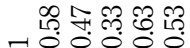 \\
\hline & 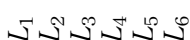 \\
\hline
\end{tabular}

Table 5.

Grey relational grade for alternatives 
The ranking of TOPSIS-GRA method when compared with fuzzy TOPSIS and fuzzy VIKOR methods is very similar. The ranking in the proposed methodology and fuzzy TOPSIS is exactly the same, whereas when compared with fuzzy VIKOR, the rankings are similar except for the rankings of $L_{2}, L_{4}, L_{5}$ and $L_{6}$. The changes in rankings are due to the highly competitive nature of the locations selected. As there is no MCDM method which can guarantee the optimal solution in absolute terms, the comparison with one or more methods justifies the results of the proposed method. Further, sensitivity analysis validates the robustness of the suggested methodology.

Further, the resolving coefficient value is used for sensitivity analysis in order to verify the robustness of the proposed method. In the analysis, various resolving coefficient values ranging from 0.1 to 1 are used. It was observed that they do not affect the ranking order of the location alternatives. But as the $\zeta$ value increases, the $\mathrm{CC}_{i}$ values of alternatives converge. For the various $\zeta$ values Table 7 establishes the varied $\mathrm{CC}_{i}$ values that rely on the extension of Burillo and Bustince's method that is subject to the Hamming separation $(d)$. As observed from the table, $L_{1}$ is the most ideal area selected as for closeness coefficient $\mathrm{CC}_{i}$. The positioning request of the area choices does not change with the adjustments in the qualities. Lastly, the ranking of priority for allocation alternatives using the results of $\mathrm{CC}_{i}$ values is achieved as $L_{1}>L_{4}>L_{6}>L_{5}>L_{3}>L_{2}$ with regard to assorted values of coefficient variable. Results of sensitivity analysis are shown in Table 7 . Also, results are also presented graphically in Figure 3.

\section{Conclusion}

The urbanization of populace and the huge move of individuals towards comfort have made new shopping patterns which have brought about the rise of round-the-clock convenience stores. In the recent years, the convenience store portion advertisement has developed and has turned out to be exceedingly aggressive, with a fight to pick up the piece of the overall industry and offer of wallet of every single buyer. Choosing the most profitable site location turns into one of the most crucial and difficult undertakings for the organization.

In this paper, a fuzzy MCDM method is presented combining fuzzy TOPSIS and GRA methods, based on the extension of Burillo and Bustince's formula based on Hamming distance, in order to evaluate and select the best location alternative for opening a convenience store. A real-world case study from NCT of New Delhi was presented to explain the suggested approach. First, the criteria that make the location alternative more suitable to open a convenience store are determined, that is, population characteristics, economic considerations, competition, consumer accessibility, store characteristics, total cost, site attractiveness and site security.

Some examples of studies in similar domain are observed and compared with this study. The ranking of the criteria in this study is compared with a couple of studies in the retail

\begin{tabular}{lcccccrr}
\hline & \multicolumn{2}{c}{$\begin{array}{c}\text { Proposed hybrid } \\
\text { fuzzy TOPSIS-GRA } \\
\text { methodology }\end{array}$} & \multicolumn{2}{c}{$\begin{array}{c}\text { Fuzzy TOPSIS } \\
\text { Location alternatives }\end{array}$} & $\mathrm{CC}_{i}$ values & Rank & \multicolumn{2}{c}{$\mathrm{CC}_{i}$ values } & Rank & \multicolumn{2}{c}{$\begin{array}{c}\text { Fuzzy VIKOR } \\
Q_{j} \text { values }\end{array}$} & Rank & \\
\hline$L_{1}$ & 1.607 & 1 & 0.128588 & 1 & 0.027401901 & 1 & \\
$L_{2}$ & 0.919 & 6 & 0.092745 & 6 & 0.052781847 & 2 & \\
$L_{3}$ & 0.928 & 5 & 0.092943 & 5 & 0.066234786 & 5 & Table 6. \\
$L_{4}$ & 1.097 & 2 & 0.12684 & 2 & 0.069690141 & 6 & Comparative results of \\
$L_{5}$ & 1.012 & 4 & 0.093856 & 4 & 0.053533376 & 3 & different \\
$L_{6}$ & 0.986 & 3 & 0.098611 & 3 & 0.055429162 & 4 & methodologies \\
\hline
\end{tabular}

Convenience store locations prioritization

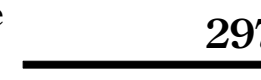


MSCRA

2,4

\section{8}

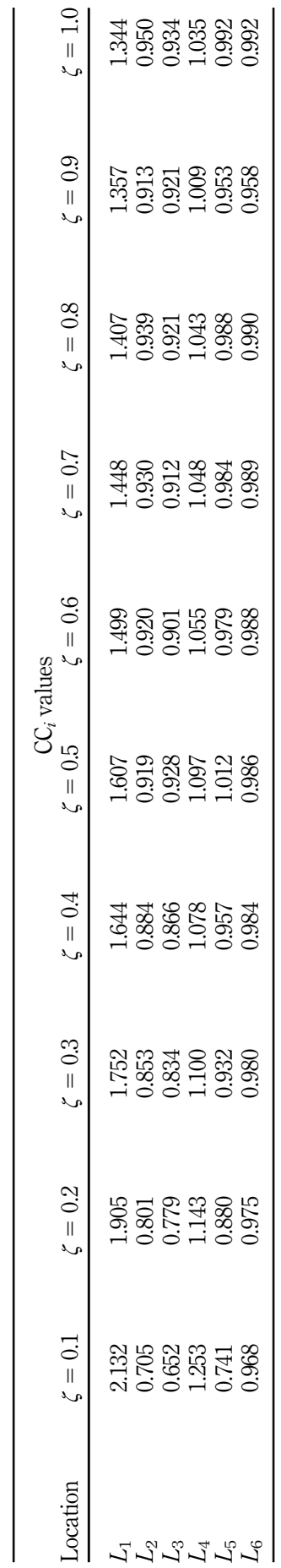

Table 7.

Sensitivity analysis results

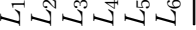


domain for developing economies. For example, in a similar study conducted in Taiwan aimed at selecting the most optimal convenience store location (Kuo et al., 2002), "Competition" emerges as the top criterion, whereas in our study based in India, "Total Cost" incurred emerges as the deciding factor. The following reason can be attributed to this observation. As the market in Taiwan already has a highly competitive landscape and the number of players are quite higher when compared to the geography considered in this study. However in India, as round-the-clock convenience store is still a relatively newer concept with fewer players and less market share, hence "Total Cost" becomes a major deciding factor.

The second example considered is of a study conducted in Istanbul, Turkey, which aims to model shopping centre site selection (Öüt et al., 2010). In their study, the deciding factor comes out to be "Total Cost", which is similar to our study. The second most important factor is "Economical", whereas in our study it is "Population characteristics". The reason for this observation can be attributed to the scale of investment in both the cases, as to set up a shopping centre investment is fairly high, hence the return on investment and estimated profits become a major attribute but to set up a convenience store the investment is much lower.

Additionally the main theoretical contribution and scientific value addition of this paper can be stated as follows:

(1) The first and foremost contribution of this study is usage of objective weight value as calculated by the fuzzy AHP to replace the subjective weight that DMs set directly that is, the objective weight of the fuzzy AHP is used instead of the subjective weight, which reduces the bias that may be caused by the subjective judgment.

(2) Second contribution is to integrate the TOPSIS method with GRA techniques in a fuzzy environment to assess and rank the location alternatives. The closeness coefficient is used as the evaluation basis for appropriate selection of the location alternative.

(3) Further, to check the heftiness and robustness of the created structure, sensitivity analysis is likewise performed. It is observed that outcomes do not change under various settling coefficient values, demonstrating that the proposed structure for area choice is very robust. The suggested methodology is verified and compared with results of other MCDM tools of prominence such as fuzzy TOPSIS and fuzzy VIKOR.

The criteria weights, dependent on experts' assessments, are calculated by fuzzy AHP. The proposed hybrid fuzzy TOPSIS-GRA technique is utilized to assess the location alternatives. A direct implication of this study is that this system might be utilized by various retail organizations in both the private sector as a strategy to expand their current offerings and chain of stores. Apart from the criteria considered in the study, the retailers might decide to add or remove any existing criteria in relation to their convenience store and unique user

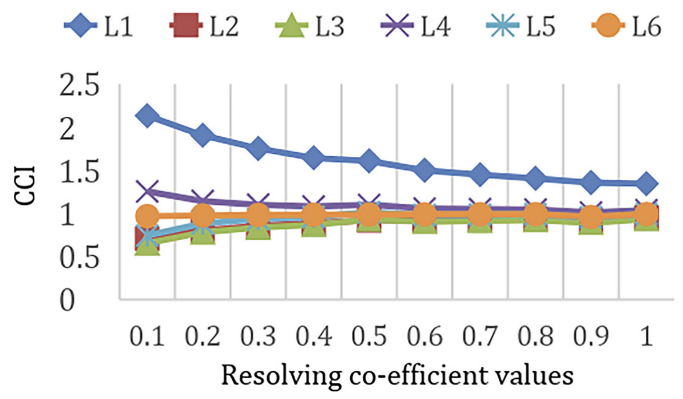

Figure 3.

Sensitivity analysis of $\mathrm{CC}_{i}$ values for each alternative
Convenience store locations prioritization

299 
MSCRA

2,4

300

behaviour. The proposed methodology might be utilized in various metropolitan urban areas in India and abroad. The framework can be utilized by both the central and state government agencies to establish and expand their set of public ration stores.

There are some limitations to this research. Firstly, we have taken into account only eight selection criteria, but additional criteria such as environmental considerations, labour availability could further enhance ranking results. We have also considered experts' opinions based on the questionnaire and interviews. Secondly, the proposed method can be also be used and applied to evaluate location alternatives in other cities in India and also in other major cities of the world for establishing retail stores.

In future, different MCDM methods such as Multi-Objective Optimization on the basis of Ratio Analysis (MOORA), Elimination and Choice Translating Reality (ELECTRE), Preference Ranking Organization Method for Enrichment Evaluation (PROMETHEE), Complex Proportional Assessment (COPRAS) can be used as alternative performance evaluation techniques. Furthermore, Stochastic Multi-Criteria Decision-Making methods (SMCDM) such as Stochastic AHP, ANP and SVIKOR (Stochastic Visekriterijumska Optimizacija I Kompromisno Resenj) can be applied and compared to check the validity of our findings.

\section{References}

Arsovski, S., Todorovic, G., Lazić, Z., Arsovski, Z., Ljepava, N. and Aleksic, A. (2017), "Model for selection of the best location based on fuzzy AHP and Hurwitz methods", Mathematical Problems in Engineering, Vol. 2017, 2803461, p. 12.

Bai, C. and Satir, A. (2020), "Evaluating green supplier satisfaction”, Modern Supply Chain Research and Applications, Vol. 2 No. 2, pp. 63-81.

Berman, B. and Evans, J.R. (1995), "Retail management: a strategic approach”, Doctoral Dissertation, Univerza v Mariboru, Ekonomsko-Poslovna Fakulteta.

Buckley, J.J. (1985), "Fuzzy hierarchical analysis”, Fuzzy Sets and Systems, Vol. 17 No. 3, pp. 233-247.

Burnaz, S. and Topcu, Y.I. (2006), "A multiple-criteria decision-making approach for the evaluation of retail location”, Journal of Multi-Criteria Decision Analysis, Vol. 14, pp. 67-76.

Burillo, P. and Bustince, H. (1996), "Entropy on intuitionistic fuzzy sets and on interval-valued fuzzy sets", Fuzzy Sets and Systems, Vol. 78, pp. 305-316.

Büyüközkan, G. (2004), "Multi-criteria decision making for e-marketplace selection”, Internet Research, Vol. 14 No. 2, pp. 139-154.

Chakravorty, M. (2019), "Indian Retailers revisit consumer strategy from mass marketing to intelligence based targeted approach", India Retail Forum, Deloitte India, available at: https:// www2.deloitte.com/in/en/pages/consumer-business/articles/retail-leadership-summit-2019.htm (accessed 26 August 2020).

Chang, H. and Hsieh, C.M. (2014), "A TOPSIS model for chain store location selection”, Review of Integrative Business and Economics Research, Vol. 4 No. 1, pp. 410-416.

Chen (2019), "A new multi-criteria assessment model combining GRA techniques with intuitionistic fuzzy entropy-based TOPSIS method for sustainable building materials supplier selection", Sustainability, Vol. 11 No. 8, pp. 1-18.

Cottrell, J.L. (1973), "An environmental model for performance measurement in a chain of supermarket”, Journal of Retailing, Vol. 49 No. 3, pp. 51-63.

Craig, C.S. (1984), "Models of the retail location process: a review", Journal of Retailing, Vol. 60 No. 1 , pp. 5 -36.

Dubois, D. and Prade, H. (1980), Fuzzy Sets and Systems: Theory and Applications, Academic Press, Boston.

Erbıyık, H., Özcan, S. and Karaboğa, K. (2012), "Retail store location selection problem with multiple analytical hierarchy process of decision making an application in Turkey", Procedia-Social and Behavioral Sciences, Vol. 58 No. 1, pp. 1405-1414. 
Ge, D., Hu, L., Jiang, B., Su, G. and Wu, X. (2019), "Intelligent site selection for bricks-and-mortar stores", Modern Supply Chain Research and Applications, Vol. 1 No. 1, pp. 88-102.

Gupta, S., Ahuja, G. and Kumar, G. (2018), "Identification of optimum locations for charging of electric vehicles", 2018 7th International Conference on Reliability, Infocom Technologies and Optimization (Trends and Future Directions) (ICRITO), Noida, 2018, pp. 867-872.

Gupta, S., Soni, U. and Kumar, G. (2019), "Green supplier selection using multi-criterion decision making under fuzzy environment: a case study in automotive industry", Computers and Industrial Engineering, Vol. 136, pp. 663-680.

Hoch, S.J., Kim, B.D., Montgomery, A.L. and Rossi, P.E. (1995), "Determinants of store-level price elasticity", Journal of Marketing Research, Vol. 32 No. 1, pp. 17-29.

Ingene, C.A. and Brown, J.R. (1987), "The structure of gasoline retailing”, Journal of Retailing, Vol. 63 No. 4 , p. 365.

Irwin, B. (1986), Basic Retailing, Irwin, Illinois.

Işıklar, G. and Büyüközkan, G. (2007), "Using a multi-criteria decision making approach to evaluate mobile phone alternatives", Computer Standards and Interfaces, Vol. 29 No. 2, pp. 265-274.

Jones, M., Mothersbaugh, D. and Beatty, S. (2003), "The effects of locational convenience on customer repurchase intentions across service types", Journal of Services Marketing, Vol. 17, pp. 701-712.

Karande, K. and Lombard, J.R. (2005), "Location strategies of broad-line retailers: an empirical investigation”, Journal of Business Research, Vol. 58, pp. 687-695.

Kaufmann, A. and Gupta, M.M. (1991), Introduction to Fuzzy Arithmetic: Theory and Applications, VanNostrand Reinhold, New York.

Kaufmann, P.J., Donthu, N. and Brooks, C.M. (2000), "Multi-unit retail site selection processes: incorporating opening delays and unidentified competition", Journal of Retailing, Vol. 76 No. 1, pp. 113-127.

Kumar, A., Kashyap, H., Malhotra, H., Rawat, K., Kumar, G. and Soni, U. (2019), "Preferential selection of locations for installing CCTV using fuzzy TOPSIS approach: a case study for North Delhi”, 2019 Twelfth International Conference on Contemporary Computing (IC3), Noida, pp. 1-7.

Kuo, R.J., Chi, S.C. and Kao, S.S. (2002), "A decision support system for selecting convenience store location through integration of fuzzy AHP and artificial neural network", Computers in Industry, Vol. 47 No. 2, pp. 199-214.

LBS (2013), "Hangout haven" available at: https://www.businesstoday.in/magazine/lbs-case-study/ london-business-school-case-study-on-7-eleven/story/194769.html (accessed 15 November 2019).

Malik, S., Kumari, A. and Agrawal, S. (2015), "Selection of locations of collection centers for reverse logistics using GTMA", Materials Today: Proceedings, Vol. 2 Nos 4-5, pp. 2538-2547.

Mendes, A.B. and Themido, I.H. (2004), "Multi-outlet retail site location assessment", International Transactions in Operational Research, Vol. 11 No. 1, pp. 1-18.

Nyaoga, R., Magutu, P. and Wang, M. (2016), “Application of Grey-TOPSIS approach to evaluate value chain performance of tea processing chains", Decision Science Letters, Vol. 5 No. 3, pp. 431-446.

Olson, D.L. (2004), "Comparison of weight in TOPSIS models", Mathematical and Computer Modelling, Vol. 40, pp. 721-727.

Önüt, S., Efendigil, T. and Kara, S.S. (2010), "A combined fuzzy MCDM approach for selecting shopping center site: an example from Istanbul, Turkey", Expert Systems with Applications, Vol. 37 No. 3, pp. 1973-1980.

PWC (2017), “The promise of Indian retail”, available at: https://www.pwc.in/assets/pdfs/publications/ 2017/the-promise-of-indian-retail-from-vision-to-execution.pdf (accessed 12 November 2019).

Roig-Tierno, N., Baviera-Puig, A., Buitrago-Vera, J. and Mas-Verdu, F. (2013), "The retail site location decision process using GIS and the analytical hierarchy process", Applied Geography, Vol. 40, pp. 191-198.
Convenience

store locations prioritization 
MSCRA

2,4

\section{2}

Shan, W., Yan, Q., Chen, C., Zhang, M., Yao, B. and Fu, X. (2019), "Optimization of competitive facility location for chain stores", Annals of Operations Research, Vol. 273 Nos 1-2, pp. 187-205.

Singh, R.K., Chaudhary, N. and Saxena, N. (2018), "Selection of warehouse location for a global supply chain: a case study", IIMB Management Review, Vol. 30 No. 4, pp. 343-356.

Torfi, F.A., Farahani, R.Z. and Rezapour, S. (2009), "Fuzzy AHP to determine the relative weights of evaluation criteria and Fuzzy TOPSIS to rank the alternatives", Applied Soft Computing, Vol. 10 No. 2, pp. 520-528.

Turhan, G., Akalı, M. and Zehir, C. (2013), "Literature review on selection criteria of store location based on performance measures", Procedia - Social and Behavioral Sciences, Vol. 99, pp. 391-402.

Tzeng, G.H., Teng, M., Chen, J.J. and Opricovic, S. (2002), "Multicriteria selection for a restaurant location in Taipei", International Journal of Hospitality Management, Vol. 21 No. 2, pp. 171-187.

Yang, C.L., Chuang, S.P., Huang, R.H. and Tai, C.C.. (2008), "Location selection based on AHP/ANP approach", IEEE International Conference on Industrial Engineering and Engineering Management, Singapore, pp. 1148-1153.

Yap, J.Y.L., Ho, C.C. and Ting, C.Y. (2019), "A systematic review of the applications of multi-criteria decision-making methods in site selection problems", Built Environment Project and Asset Management, Vol. 9 No. 4, pp. 548-563.

\section{Corresponding author}

Parnika Tyagi can be contacted at: parnikatyagi15@gmail.com

For instructions on how to order reprints of this article, please visit our website:

www.emeraldgrouppublishing.com/licensing/reprints.htm

Or contact us for further details: permissions@emeraldinsight.com 